\title{
Biomarkers and non-invasive tests for gastrointestinal mucositis
}

\author{
N. S. S. Kuiken ${ }^{1,2}$ • E. H. H. M. Rings ${ }^{3,4}$ • N. M. A. Blijlevens ${ }^{5}$ - Wim J. E. Tissing ${ }^{1}$
}

Received: 17 October 2016 / Accepted: 12 May 2017 /Published online: 24 May 2017

(C) The Author(s) 2017. This article is an open access publication

\begin{abstract}
Gastrointestinal mucositis is a complex inflammatory reaction of the mucous membranes, a side effect of both chemotherapy and radiotherapy. Currently, assessment scales are used to diagnose mucositis. However, a biomarker which would determine whether there is mucositis and thereby establish the severity objectively would be very useful. This will give the opportunity to evaluate studies, to determine risk factors and incidence, and it will make it possible to compare studies. Moreover, this biomarker might improve clinical management for patients. In this paper, we reviewed studies concerning potential biomarkers in blood samples and fecal samples, and potential tests in breath samples and urine samples. We include biomarkers and tests studied in animal models and/or in clinical trials, and discuss the validity, diagnostic accuracy, and applicability.
\end{abstract}

Keywords Gastrointestinal mucositis · Biomarkers · Citrulline

Wim J. E. Tissing

w.j.e.tissing@umcg.nl

1 Department of Pediatric Oncology, Beatrix Children's Hospital, University Medical Center Groningen, University of Groningen, PO Box 30001, 9700 RB Groningen, The Netherlands

2 Department of Pediatric Gastroenterology and Hepatology, Beatrix Children's Hospital, University Medical Center Groningen, University of Groningen, Groningen, The Netherlands

3 Department of Pediatrics, Leiden University Medical Center, Leiden University, Leiden, The Netherlands

4 Department of Pediatrics, Erasmus Medical Center Rotterdam, Erasmus University Rotterdam, Rotterdam, The Netherlands

5 Department of Hematology, Radboud University Medical Center, Radboud University Nijmegen, Nijmegen, The Netherlands

\section{Introduction}

Mucositis is a severe side effect of both chemotherapy and radiotherapy in several cancer treatment protocols. It comprises complex inflammatory damage to the mucosa of the complete alimentary tract. Gastrointestinal mucositis, further referred to as mucositis, is complex and the pathophysiology can be based on the five-phase pathophysiological model of oral mucositis $[1,2]$. However, the exact working mechanism has not been elucidated. Patients suffer from abdominal pain, vomiting, and diarrhea, with consequently weight loss, nutritional support, and an increased risk to develop a sepsis or bacteremia $[3,4]$.The incidence of mucositis is estimated at $40-100 \%$ of patients with chemotherapy, dependent of treatment and patient-related factors $[4,5]$. The estimation of the incidence is such a broad range, since there is no gold standard for diagnosis and assessment of the severity of mucositis. The therapy of cancer has been changed in the past years to more targeted therapies. However, the effect of these targeted therapies on the risk, severity, and incidence of mucositis is unknown. It is thought that there is an underreporting of mucositis due to a lack of a gold standard [6]. Ideally, for the diagnosis and severity of mucositis, inspection of the small intestine microscopically would be necessary. Therefore, the gold standard would be a biopsy from the small intestine. However, an endoscopy is invasive, can be painful, the small intestine is only visible for a small part, and moreover, this test is not preferable in an immune-compromised patient since there is a high risk of infection and bleeding. The intestinal tissue is vulnerable during mucositis. Therefore, clinical practice is in need of a test to diagnose and assess the severity of mucositis. An optimal test to diagnose mucositis and establish the severity will give the opportunity to evaluate studies, to determine risk factors and incidence, and if used in all studies, it will make it possible to compare them. Moreover, this optimal test 
will potentially improve management in for example prophylactic antibiotic use, or diet changes for nutritional support.

The clinical way to determine the severity of mucositis to date is the use of an assessment scale. There are a few assessment scales developed to determine the severity of mucositis, like the National Cancer Institute Common Terminology Criteria for Adverse Events (NCI-CTCAE) scale and the Daily Gut Score (DGS) $[3,7,8]$. These scoring scales are based on several aspects like vomiting, diarrhea, pain, abdominal complaints, and nutritional support. Moreover, several hospitals have developed their own assessment scale for mucositis; the use of these many different scales makes it difficult to compare studies and improve the clinical practice. More importantly, these assessment scales are subjective, based on symptoms not very specific for mucositis, influenced by pain relief medication, and have not been validated for the use in young children [3]. Therefore, a biomarker which would determine whether there is mucositis and thereby establish the severity objectively would be very useful. Several potential biomarkers and tests have been studied, both preclinical and clinical. In a few reviews about biomarkers, several possible biomarkers were already discussed. [9-12]. In this review, we give an update including new studies from recent years concerning potential biomarkers in blood samples and fecal samples, and potential tests in breath samples and urine samples. We include biomarkers and tests studied in animal models and/or in clinical trials.

\section{Definition of biomarker}

The terminology around biomarkers is broad. The question is when is a measured sample a biomarker? The Biomarkers Definition Working Group mentioned a biomarker as "a characteristic that is objectively measured and evaluated as an indicator of normal biological processes, pathogenic processes, or pharmacologic responses to a therapeutic intervention" [13]. Another, more specific recommendation for a definition was "human or animal biological property whose in vitro measurement or identification is useful for the prevention, diagnosis, prognosis, treatment, and follow-up of human or animal diseases, and for their understanding" [14]. In this review, we will use this second definition. In respect to mucositis, a biomarker should diagnose mucositis and should determine the severity of mucositis. Moreover, this biomarker should be easily accessible, non-invasive, and sequentially determinable. This means in our opinion that a biomarker should be present in the human body without adding something from outside the body to measure a response. In other words, this biomarker is present in healthy individuals and is altered, either higher or lower, due to mucositis. We interpret the use of a substitute that has to be administered to the patient in any way more as a test to determine the severity of damage to the mucosa. Therefore, we make a division in biomarkers, which are actually present in the body, and tests, which need the administration of any kind of substrate to the patient before measurement. To evaluate the usefulness of a biomarker or test in the diagnosis of a disease, three aspects should be included. First, the validity of the biomarker or test shows if the result matches the severity of the disease and whether it classifies the patient correctly. Second, the diagnostic accuracy determines the chance that a patient with a positive test or biomarker has the disease, and the chance that a patient with a normal biomarker of test has the disease. Finally, the applicability values if the biomarker or test is feasible and cost effective in the specific patient group. Therefore, in this review, we value all biomarkers and tests for mucositis on these three points: the validity, the diagnostic accuracy, and the applicability, although this is challenging due to the absence of a gold standard.

\section{Potential biomarkers in blood samples}

\section{Citrulline}

One of the most significant potential biomarkers for mucositis is citrulline in blood samples, measurable in both serum and plasma. The intestine is the primary source for the amount of citrulline present in the blood circulation [15]. Citrulline is a non-protein amino acid, synthesized almost exclusively by the enterocytes of the small intestine. It is synthesized in the enterocyte from glutamine, and only released in the circulation as a masked form of arginine, to bypass the uptake of arginine by the liver, and to be converted back to arginine in the kidneys [11]. In fact, citrulline is an intermediary product of amino acid metabolism [16]. Crenn et al., showed that plasma citrulline correlates with the small bowel length, and that it is a potential biomarker of small intestinal enterocyte mass in patients with celiac disease $[16,17]$. Moreover, in more than 500 patients suffering from several intestinal diseases, plasma citrulline was shown as biomarker for the enterocyte mass reflecting the absorptive capacity of the small intestine [18]. Lastly, citrulline has been shown not to be influenced by inflammation or by the nutritional intake, since diet seems to be a poor source of citrulline [11, 18, 19]. Unfortunately, plasma citrulline level cannot be used as biomarker in case of renal failure if creatinine clearance is below $50 \mathrm{ml} / \mathrm{min}$, since this increases the citrulline level in the blood $[18,20]$ (in clinical practice, probably a creatinine clearance below $30 \mathrm{ml} / \mathrm{min}$ is relevant, personal experience).

Citrulline can be accurately measured in little volumes, even in $30 \mu \mathrm{l}$. It is measured by automated ion exchange column chromatography $[21,22]$. During mucositis, the enterocyte mass significantly decreases. Therefore, citrulline is expected to decrease during mucositis, which represents the 
enterocyte mass and thereby, the absorptive capacity during mucositis. Therefore, several studies have been performed to determine plasma or serum citrulline as a possible marker for mucositis.

In preclinical studies, it was shown that plasma citrulline correlates significantly with the villus length in a methotrexate-induced mucositis rat model [23]. Furthermore, preclinical studies showed that the use of plasma citrulline corresponded with radiation-induced mucositis in rats and mice [24, 25]. Even more, plasma citrulline correlated with the digestion and absorption of lactose and fatty acids during mucositis in rats $[23,26]$.

One of the first clinical studies concerning the possibility of plasma citrulline as biomarker was determined by Blijlevens et al., [27]. It was shown that low serum citrulline levels corresponded with severe mucosal barrier injury, measured with the daily gut score and sugar permeability test, in patients receiving hematopoietic stem cell transplantation [27, 28]. Furthermore, it was also determined that serum citrulline levels decreased during radiotherapy, correlating with the severity of mucositis, making it also suitable in radiotherapyinduced mucositis [29]. In 2009, plasma citrulline was compared with several other methods to diagnose mucositis, like the NCI-CTCAE mucositis scoring scale, daily gut score, plasma interleukin-8, fecal interleukin-8, fecal calprotectin, and the sugar absorption test in pediatric cancer patients with GI mucositis [30]. The authors showed that of all parameters, plasma citrulline correlated the strongest with the daily gut score and the NCI-CTCAE scale, and possibly can even detect mucositis if it is not clinically overt [30]. In adult HSCT patients, bacteremia coincided with low plasma citrulline levels [31]. Furthermore, it has been suggested to use a citrulline based assessment score [32]. In 2013, Van der Velden and colleagues investigated the use of plasma citrulline and albumin as a possible biomarker for mucositis in adult patients receiving hematopoietic stem cell transplantation [33]. They concluded that plasma citrulline is the most potent biomarker; it might be useful in the clinical decision making, for therapeutic interventions or nutritional support [33]. In another pilot study, the authors also showed that serum citrulline is decreased after the conditioning regimen for HSCT in adult patients due to intestinal damage [34]. A more recent study determined the value of citrulline as biomarker in pediatric patients receiving HSCT [35]. They concluded that serum citrulline correlated with gastrointestinal function, determined with a combination of oral mucositis score, pro-inflammatory cytokines, oral intake, bodyweight change, and graft-versushost disease, in children undergoing HSCT [35].

In the past years, a few reviews concerning biomarkers for mucositis were published [9, 10, 12]. A more detailed review about citrulline as biomarker for mucositis was published in 2014 by Barzal et al. [11]. We conclude that citrulline is a biomarker of mucositis, based on the abovementioned definition. It correlates with the severity of mucositis and is sequentially detectable; therefore, the applicability and validity of citrulline seems good. However, we cannot draw any conclusions about the diagnostic accuracy, because more research is needed to answer these questions.

\section{Cytokines}

In the pathophysiology of mucositis, which is not yet completely elucidated, pro-inflammatory cytokines like TNF- $\alpha$, IL1-beta, and IL-6 are important. Increased levels of cytokines are determined during mucositis in both animal models and clinical trials $[36,37]$. Therefore, these cytokines are also a potent biomarker for mucositis. These proinflammatory cytokines represent the inflammatory part of the mucositis pathophysiology.

One of the major concerns for the use of cytokines as biomarker is that the determination of cytokines during mucositis is critically time dependent [38]. However, Bowen et al. determined in a pilot study in patients with esophageal cancer, treated with both chemotherapy and radiotherapy, the value of pro-inflammatory genes as predictive value. They concluded that mRNA of TNF- $\alpha$ was consistently increased in the patients suffering from gastrointestinal toxicity [39]. However, this was only a small sample size in a specific patient group, and moreover, they studied gastrointestinal toxicity in general, of which one was mucositis. Furthermore, in pediatric oncology patients, interleukin-8 (IL-8) only correlated with the daily gut score and the NCI-CTCAE scale in patients with febrile neutropenia [30]. Furthermore, as shown in other studies, IL-8 is effective for determining febrile neutropenia [40, 41]. Therefore, IL-8 is probably useful in determining infections in general.

Mucositis is a risk factor to develop fever; however, febrile neutropenia might be induced by another infection. The importance of neutrophils in the initiation of mucositis is unknown [42]. Even more, fever is often present during mucosal barrier injury with or without an infection, due to the fact that there is an immune response irrespective of the presence of any particular microbial pathogen [43]. Thus, in general, patients with mucositis are mostly complex patients with neutropenia, fever, and other causes of inflammation, for example graft-versus-host disease. This gives the most important disadvantage of the use of these cytokines as biomarkers; cytokines are non-specific for mucositis, but may reflect any inflammation present in the body. Due to too much influence of other mechanisms, the validity and diagnostic accuracy are low; cytokines are a non-specific marker for inflammation. Therefore, inflammatory cytokines like TNF- $\alpha$ does not seem to be suitable as a biomarker for mucositis, according to the biomarker definition mentioned above. 


\section{C-reactive protein}

C-reactive protein (CRP) is used in clinical practice as an acute phase protein increased in case of an inflammation. During mucositis, there is inflammation in the intestine, suggesting to increasing the CRP in the blood. However, Miedema et al. determined that CRP increases only late after onset of fever and concluded that it is a late marker for febrile neutropenia [40]. This is probably also the case for mucositis. Moreover, as already mentioned for the pro-inflammatory cytokines, the validity and diagnostic accuracy of CRP are low, since it is also influenced by many other inflammatory mechanisms often present in the patient suffering from mucositis, like infections. Therefore, CRP is probably not a valuable biomarker for mucositis.

\section{Intestinal fatty acid binding protein and ileal-bile acid binding protein}

Intestinal fatty acid binding protein (I-FABP), an endogenous cytosolic enterocyte protein, and ileal bile acid binding protein (I-BABP), present in enterocytes, are both released by dying mature enterocytes and therefore possible markers of enterocyte loss in the small intestine. I-FABP has been shown to be a possible useful plasma marker for intestinal injury shown in human tissue samples and blood samples [44]. Furthermore, I-FABP has been shown to be a possible systemic marker for Crohn's disease [45]. In 2009, Derikx and colleagues showed in patients receiving conditioning regimen for HSCT that citrulline in combination with I-FABP and I-BABP possibly assess not only the enterocyte mass but also the enterocyte turnover in the small intestine [28]. No further studies with I-FABP or I-BABP in other animal experiments or clinical trials during mucositis have been performed. Therefore, no conclusions can be drawn concerning the validity, diagnostic accuracy, and applicability. In respect to the definition of a biomarker for mucositis, these markers need further research to draw any conclusion; however, these proteins might be potentially useful.

\section{Potential biomarkers in feces samples}

\section{Granulocyte marker proteins}

Fecal calprotectin and calgranulin (S100A12) are granulocyte marker proteins which are possible markers of intestinal inflammation [46]. Calprotectin in fecal samples has been used in many diseases concerning inflammation in the intestine. In a clinical trial with many patients with several intestinal inflammatory disorders, it was shown that fecal calprotectin levels were increased compared to healthy controls $[47,48]$. Fecal calgranulin (S100A12) has also been shown to be a marker for inflammatory bowel disease [46]. Therefore, granulocyte marker proteins seem to be reliable markers of intestinal inflammation. During mucositis, there is indeed inflammation in the intestine. However, in contrast to animal models, during chemotherapy-induced mucositis in humans, there is often neutropenia; there is no influx of myeloid cells. Since there is neutropenia in most of the patients suffering from mucositis, calprotectin and calgranulin will not be increased in these patients. This has been shown in a small study with pediatric cancer patients, where fecal calprotectin was undetectable in most samples, probably due to the fact that these patients were neutropenic [30]. Therefore, during chemotherapy-induced mucositis, calprotectin and calgranulin are probably not useful biomarkers. However, the granulocyte marker protein has been shown to be a possible marker during radiation-induced mucosal damage in rats [49]. Patients receiving radiation and suffering from mucosal damage are most of the times not neutropenic; therefore, calprotectin or calgranulin might indeed be a possible biomarker for these specific patients $[50,51]$. Therefore, for these biomarkers, there should be a division between radiation-induced mucositis and chemotherapyinduced mucositis. Currently, no conclusions can be drawn concerning the validity, diagnostic accuracy, and the applicability. Fecal calprotectin or fecal calgranulin might be a biomarker for radiation-induced mucositis, but we are in need of clinical trials to draw any conclusion.

\section{Ratio fecal human DNA/total DNA}

Another possible biomarker in feces samples is the ratio fecal human DNA/total DNA. With this ratio, the loss of enterocytes can be measured. This ratio was studied as a possible biomarker in pediatric cancer patients suffering from mucositis. Van Vliet et al. showed no significant increase in the ratio during mucositis; however, the fecal DNA ratio did correlate with both the DGS and the NCI-CTCAE criteria in pediatric cancer patients [30]. So the ratio fecal human DNA/ total DNA might indicate loss of enterocytes during mucositis; however, no further research has been performed. The fecal DNA ratio is a possible marker for mucositis, but no conclusions can be drawn concerning the validity, diagnostic accuracy, and applicability without further research.

\section{Potential tests of intestinal damage in urine or breath samples}

\section{Sugar permeability test}

The sugar permeability test was developed to test the gut barrier function using a non-invasive method. For this 
test, the patient has to ingest a hypertonic solution with monosaccharide, like L-rhamnose, and disaccharide, like lactulose, sugars which are not metabolized. Mono saccharides represent the transcellular route of absorption, and disaccharides represent the paracellular route of absorption. These sugars are almost unchanged excreted in the urine. Therefore, the measured levels in urine represent the permeability of the gut, where monosaccharides represent the absorption surface area and disaccharides represent the permeability of tight junctions of the small intestine [52].

In adult HSCT patients, this sugar permeability test has shown that these patients had abnormal permeability of the gut for both sugars [53]. In another study, the sugar permeability test showed a decrease in sugars in urine [27]. However, for the sugar permeability test, urine collection during multiple hours is necessary $[9,10]$. Van vliet et al. included the sugar permeability test in a clinical trial in pediatric cancer patients to compare several tests and biomarkers for mucositis. However, sugar intake and urine collecting was problematic in pediatric cancer patients due to vomiting and severe diarrhea [30].

Previously in a review about non-invasive biomarkers for mucositis, it was already concluded that the sugar permeability test may describe the barrier function, but does not necessarily determine the absorptive capacity of the small intestine [10]. No new studies have been conducted in the last years. This test might be potential to determine the barrier function of the small intestine during mucositis. However, this is not a biomarker, according to the abovementioned definition, but it might be a possible useful test to show the effect of the ingested sugars. Currently, no conclusions can be drawn concerning the validity, diagnostic accuracy, and applicability.

\section{Hydrogen breath test}

The hydrogen breath test is based on the principle that sugars in the small intestine are malabsorbed in a damaged intestine. This causes a consequently increased amount of sugars in the colon which are metabolized by bacteria producing hydrogen. This hydrogen reaches, via the bloodstream, the lungs and is expired in the breath. Therefore, a damaged intestine will theoretically increase the hydrogen in the breath [12]. However, this test does not only result from malabsorption of sugars in the small intestine, but is also a result from the presence of certain bacteria in the colon as mentioned in other reports $[10$, $12,54]$. Moreover, the hydrogen breath test is mostly used for bacterial overgrowth $[55,56]$. During mucositis, the bacteria in the intestine are altered by multiple factors like diet and medication, especially antibiotics. Moreover, the bacteria might influence all phases of the pathophysiology of mucositis [57]. Therefore, the hydrogen breath test has a low validity and diagnostic accuracy, and is probably not a suitable test for gastrointestinal mucositis.

\section{3clactose breath test}

For the 13Clactose test, the lactose has to be ingested and this will be digested in the small intestine by lactase, then metabolized in the liver and expired via the breath [12]. The 13Clactose breath test combined with the hydrogen breath test was shown to be more effective to determine mucosal damage than the hydrogen breath test alone [12, 58]. However, for the $13 \mathrm{c}$ lactose breath test, intestinal lactase is the most important factor, and it has been shown that a lot of people normally have low lactase activity $[10,58]$. Therefore, the $13 \mathrm{c}$ lactose breath test is not a suitable marker for mucositis, because the validity, diagnostic accuracy, and applicability are all low.

\section{Sucrose breath test}

One of the possible tests is the 13C-sucrose breath test (SBT). For the SBT, patients have to ingest $13 \mathrm{C}$-sucrose. This will be digested in the intestine by sucrase, in the liver metabolized, and eventually expired in the breath [10]. Therefore, SBT seems to be a possible marker for digestive enzymes and enterocytes in the small intestine, an indicator for small bowel function [10]. Mucositis is a complex mechanism, but one of the clear features is villus atrophy in the small intestine, with a consequently decreased absorption area and a decreased amount of digestive enzymes. Therefore, the SBT is a potential test to determine the severity of mucositis and will show a decreased amount of $13 \mathrm{CO} 2$ in the expired breath if there is damage to the intestine. A few studies in animal models have shown that SBT is a possible marker for mucositis [59-62]. Tooley et al. performed a small clinical trial in pediatric cancer patients, and concluded that SBT possibly non-invasively detect gut damage [63]. However, this was a small sample size [64]. Furthermore, so far, this is the only clinical trial performed with SBT during mucositis. To measure the SBT, breath samples have to be taken every 15 min during a few hours, multiple times during admission $[9,12]$. This is for the pediatric cancer patients really invasive and difficult for the very young children. However, this test was feasible in children with diarrhea, not cancer treatment related, where the SBT value was significantly decreased compared to healthy control, suggesting a decreased absorption capacity [65]. The current knowledge shows a promising validity, an unknown diagnostic accuracy, and conflicting findings concerning the applicability. Therefore, more clinical trials are needed to draw conclusions about the validity, diagnostic accuracy, and applicability of this SBT during mucositis and thereby to determine whether it is a potential test to diagnose mucositis (Table 1). 
Table 1 Potential biomarkers and tests

\begin{tabular}{|c|c|c|}
\hline Potential biomarker & Advantages & Disadvantages \\
\hline \multicolumn{3}{|l|}{ Blood } \\
\hline Citrulline & $\begin{array}{l}\text { Marker for enterocyte mass } \\
\text { Sequentially detectable } \\
\text { Correlates with mucosal damage in animal models } \\
\quad \text { and clinical trials }\end{array}$ & Not useful in renal failure (if creatinine clearance is $<50 \mathrm{ml} / \mathrm{min}$ ) ${ }^{\mathrm{a}}$ \\
\hline Cytokines & Correlates with inflammation & Non-specific marker for inflammation \\
\hline C-reactive protein & Correlates with inflammation & $\begin{array}{l}\text { Non-specific marker for inflammation } \\
\text { Late marker, increases after fever }\end{array}$ \\
\hline I-FABP & Enterocyte turnover in combination with citrulline & $\begin{array}{l}\text { Short half-life time } \\
\text { Only of value in combination with citrulline }\end{array}$ \\
\hline I-BABP & Enterocyte turnover in combination with citrulline & $\begin{array}{l}\text { Short half-life time } \\
\text { Only of value in combination with citrulline }\end{array}$ \\
\hline \multicolumn{3}{|l|}{ Feces } \\
\hline $\begin{array}{l}\text { Granulocyte marker } \\
\text { proteins }\end{array}$ & Correlate with leucocyte count & Not useful during neutropenia \\
\hline Calprotectin & Correlates with inflammation & $\begin{array}{l}\text { Not detectable during neutropenia, not useful in most patients with } \\
\text { chemotherapy-induced mucositis }\end{array}$ \\
\hline Calgranulin (S100A12) & Correlates with inflammation & $\begin{array}{l}\text { Not detectable during neutropenia, not useful in most patients with } \\
\text { chemotherapy-induced mucositis }\end{array}$ \\
\hline $\begin{array}{r}\text { Ratio fecal human } \\
\text { DNA/total DNA }\end{array}$ & Marker for enterocyte loss & Time consuming, less useful in acute clinical phase \\
\hline \multicolumn{3}{|l|}{ Potential tests } \\
\hline \multicolumn{3}{|l|}{ Urine } \\
\hline Sugar permeability test & Non-invasive & $\begin{array}{l}\text { No direct measurement: collection of urine during longer duration } \\
\text { Not absorptive measurement }\end{array}$ \\
\hline \multicolumn{3}{|l|}{ Breath } \\
\hline Hydrogen breath test & Simple & $\begin{array}{l}\text { Dependent on certain bacteria in colon } \\
\text { Time consuming }\end{array}$ \\
\hline Lactose breath test & Simple & $\begin{array}{l}\text { Low lactase activity } \rightarrow \text { only useful in small percentage of patients } \\
\text { Time consuming }\end{array}$ \\
\hline Sucrose breath test & $\begin{array}{l}\text { Correlates with mucosal damage in the small } \\
\text { intestine in animal experiments } \\
\text { One study shows correlation in children }\end{array}$ & $\begin{array}{l}\text { Invasive: multiple breath samples during hours } \\
\text { Specialized equipment }\end{array}$ \\
\hline
\end{tabular}

${ }^{\mathrm{a}}$ In clinical practice, probably a creatinine clearance below $30 \mathrm{ml} / \mathrm{min}$ is relevant, personal experience

\section{Discussion}

In this review, we had a critical view, based on the validity, the diagnostic accuracy, and the applicability, on several studied biomarkers and tests to diagnose mucositis and assess the severity. As mentioned above, we made a division in biomarkers, which are actually present in the body, and tests, which need the administration of any kind of substrate to the patient before measurement.

At first, we can conclude that potential biomarkers in blood samples like cytokines and CRP are not specific enough for mucositis, since there is too much influence of other inflammatory mechanisms like infections; therefore, these parameters are probably not useful as a biomarker for mucositis, in agreement with a previous review about biomarkers [9]. In contrast, the markers I-FABP and I-BABP in blood samples are indeed potentially interesting biomarkers since they are released by dying mature enterocytes; therefore, I-FABP and I-BABP are potential markers of enterocyte loss in the small intestine. However, the determination of these markers is probably critically time dependent and only of value in combination with another biomarker like citrulline for example, but further research is needed. Furthermore, in blood samples, plasma citrulline is in our opinion one of the most promising biomarker. Several studies have shown that citrulline is measurable in animal models, adult patients, and pediatric patients. It is easily detectable, sequentially measurable, and might even detect mucositis if it is not clinically overt [30].

In addition to the blood samples, the use of feces samples to measure a biomarker is interesting due to the non-invasiveness for the patient. We can conclude that the biomarkers in feces, like calprotectin and calgranulin, are promising to detect intestinal inflammation, but probably not useful in neutropenic patients. However, during radiation-induced mucositis, they 
are indeed promising and more research is needed. Furthermore, the ratio fecal human DNA/total DNA is also interesting and more research is needed. However, it is really time consuming to determine this ratio and therefore probably less useful as biomarker in the acute clinical phase.

Besides possible biomarkers present in the body, the use of a non-invasive test to determine mucositis is also promising. The sugar permeability test seems interesting to show the barrier function of the gut; however, in the recent years, no new studies have been performed. Other possible tests, like the hydrogen breath test and the lactose breath test, are probably not useful, since it is dependent on either certain bacteria or lactase in the intestine. In comparison, the SBT seems to be superior compared to the hydrogen breath test and the 13Clactose breath test as a possible biomarker of mucositis, as concluded previously [12]. However, although breath samples are non-invasive, due to the multiple times and long duration especially for children, this test is indeed invasive. Moreover, specialized equipment is necessary. Therefore, for the SBT, more clinical trials are necessary to draw any conclusion about the feasibility during mucositis and thereby about the usefulness.

A few studies compared several biomarkers and tests to diagnose and determine the severity of mucositis. Lutgens et al. compared the use of the sugar permeability test with citrulline for the measurement and monitoring of treatmentrelated gut damage and concluded that citrulline assay is the first choice and objective parameter [66]. Furthermore, citrulline and the sugar permeability test were studied in adult HSCT patients and citrulline was concluded to correlate the best with intestinal damage determined with the DGS score [27]. Even more, Van Vliet et al. compared several biomarkers and tests, like citrulline, IL-8, fecal calprotectin, and sugar permeability test, in pediatric cancer patients and concluded that citrulline correlated the strongest with the severity of mucositis based on assessment scores [30]. Moreover, in that study, fecal calprotectin was not detectable due to the absence of neutrophils, and the sugar permeability test was not feasible due to diarrhea and vomiting.

Furthermore, it was shown that there is a possible influence of entero-endocrine hormones, like glucagon-like-peptide 1 (GLP-1) and glucagon-like-peptide 2(GLP-2), in the pathophysiology of mucositis. We speculate that future studies should determine the usefulness of one of these hormones as a biomarker for mucositis [67].

In conclusion, mucositis is still challenging to diagnose, since the gold standard biopsy of the small intestine in not optional. Many different methods to establish the diagnosis and determine the severity of mucositis in both adult and pediatric clinical oncology settings are currently used. This makes any comparison about the diagnosis and thereby about the risk, the incidence, and the severity challenging. Moreover, what are the parameters in either a clinical trial or animal experiment to answer the question if a prevention or therapy is effective? We are in need of a biomarker or test to be able to diagnose mucositis in the clinical setting and thereby determine the severity. Second, we are in need of a biomarker or test to improve the animal experiments and clinical trials for new insights in preventive and therapeutic strategies. If we have a standard method to diagnose mucositis, we can actually compare studies for the incidence and severity of mucositis in several different clinical settings. Even more, in clinical trials, we can study a prevention or treatment in patients of which we are certain that they have mucositis determined by a standard biomarker or test. In this way, we are not studying an intervention in the complete population, which will prevent unnecessary treatment of patients who will not develop mucositis. Probably this will not be possible with only one biomarker; we are possibly in need of a combination of biomarkers or tests. We conclude that plasma citrulline seems to be one of the most promising biomarkers to date, and we suggest to use this biomarker in future clinical trials and animal experiments. More research is needed to find a combination of biomarkers or tests to determine non-invasively, sequentially mucositis and its severity.

\section{Compliance with ethical standards}

Funding This work was supported by the Dutch Cancer Society (grant number RUG 2011-5272).

Disclosure The authors declare that they have no conflicts of interest.

Open Access This article is distributed under the terms of the Creative Commons Attribution-NonCommercial 4.0 International License (http:// creativecommons.org/licenses/by-nc/4.0/), which permits any noncommercial use, distribution, and reproduction in any medium, provided you give appropriate credit to the original author(s) and the source, provide a link to the Creative Commons license, and indicate if changes were made.

\section{References}

1. Sonis ST (2004) The pathobiology of mucositis. Nat Rev Cancer 4: 277-284

2. Sonis ST (2004) A biological approach to mucositis. J Support Oncol 2:21-32 discussion 35-6

3. Kuiken NS, Rings EH, Tissing WJ (2015) Risk analysis, diagnosis and management of gastrointestinal mucositis in pediatric cancer patients. Crit Rev Oncol Hematol 94:87-97

4. Lalla RV, Bowen J, Barasch A, Elting L, Epstein J, Keefe DM, DB MG, Migliorati C, Nicolatou-Galitis O, Peterson DE, RaberDurlacher JE, Sonis ST, Elad S, Mucositis Guidelines Leadership Group of the Multinational Association of Supportive Care in Cancer and International Society of Oral Oncology (MASCC/ ISOO) (2014) MASCC/ISOO clinical practice guidelines for the management of mucositis secondary to cancer therapy. Cancer 120:1453-1461

5. Sonis ST, Elting LS, Keefe D, Peterson DE, Schubert M, HauerJensen M, Bekele BN, Raber-Durlacher J, Donnelly JP, Rubenstein 
EB, Mucositis Study Section of the Multinational Association for Supportive Care in Cancer, International Society for Oral Oncology (2004) Perspectives on cancer therapy-induced mucosal injury: pathogenesis, measurement, epidemiology, and consequences for patients. Cancer 100:1995-2025

6. Elting LS, Chang YC, Parelkar P, Boers-Doets CB, Michelet M, Hita G, Rouleau T, Cooksley C, Halm J, Vithala M, Bossi P, Escalante C, Brennan MT, On behalf of the Mucositis Study Group of the Multinational Association of Supportive Care in Cancer/International Society of Oral Oncology (MASCC/ISOO) (2013) Risk of oral and gastrointestinal mucosal injury among patients receiving selected targeted agents: a meta-analysis. Support Care Cancer

7. Peterson DE, Keefe DM, Hutchins RD, Schubert MM (2006) Alimentary tract mucositis in cancer patients: impact of terminology and assessment on research and clinical practice. Support Care Cancer 14:499-504

8. National Cancer Institute (2010) Common terminology criteria for adverse events v4.0 NCI, NIH, DHHS. NIH publication \# 09-7473. http://evs.nci.nih.gov/ftp1/CTCAE/CTCAE_4.03_2010-06-14_ QuickReference_8.5x11.pdf. Accessed May 292009.

9. Gibson RJ, Bowen JM (2011) Biomarkers of regimen-related mucosal injury. Cancer Treat Rev 37:487-493

10. Tooley KL, Howarth GS, Butler RN (2009) Mucositis and noninvasive markers of small intestinal function. Cancer Biol Ther 8: 753-758

11. Barzal JA, Szczylik C, Rzepecki P, Jaworska M, Anuszewska E (2014) Plasma citrulline level as a biomarker for cancer therapyinduced small bowel mucosal damage. Acta Biochim Pol 61:615631

12. Wardill HR, Bowen JM, Gibson RJ (2013) Biomarkers of small intestinal mucosal damage induced by chemotherapy: an emerging role for the 13C sucrose breath test. J Support Oncol 11:61-67

13. Biomarkers Definitions Working Group (2001) Biomarkers and surrogate endpoints: preferred definitions and conceptual framework. Clin Pharmacol Ther 69:89-95

14. Fuentes-Arderiu X (2013) What is a biomarker? It's time for a renewed definition. Clin Chem Lab Med 51:1689-1690

15. Windmueller HG, Spaeth AE (1981) Source and fate of circulating citrulline. Am J Phys 241:E473-E480

16. Crenn P, Coudray-Lucas C, Thuillier F, Cynober L, Messing B (2000) Postabsorptive plasma citrulline concentration is a marker of absorptive enterocyte mass and intestinal failure in humans. Gastroenterology 119:1496-1505

17. Crenn P, Vahedi K, Lavergne-Slove A, Cynober L, Matuchansky C, Messing B (2003) Plasma citrulline: a marker of enterocyte mass in villous atrophy-associated small bowel disease. Gastroenterology 124:1210-1219

18. Crenn P, Messing B, Cynober L (2008) Citrulline as a biomarker of intestinal failure due to enterocyte mass reduction. Clin Nutr 27: 328-339

19. Boukhettala N, Leblond J, Claeyssens S, Faure M, Le Pessot F, Bole-Feysot C, Hassan A, Mettraux C, Vuichoud J, Lavoinne A, Breuille D, Dechelotte P, Coeffier M (2009) Methotrexate induces intestinal mucositis and alters gut protein metabolism independently of reduced food intake. Am J Physiol Endocrinol Metab 296: E182-E190

20. Ceballos I, Chauveau P, Guerin V, Bardet J, Parvy P, Kamoun P, Jungers $P$ (1990) Early alterations of plasma free amino acids in chronic renal failure. Clin Chim Acta 188:101-108

21. Demacker PN, Beijers AM, van Daal H, Donnelly JP, Blijlevens NM, van den Ouweland JM (2009) Plasma citrulline measurement using UPLC tandem mass-spectrometry to determine small intestinal enterocyte pathology. J Chromatogr B Analyt Technol Biomed Life Sci 877:387-392
22. van Eijk HM, Rooyakkers DR, Deutz NE (1993) Rapid routine determination of amino acids in plasma by high-performance liquid chromatography with a 2-3 microns Spherisorb ODS II column. J Chromatogr 620:143-148

23. Fijlstra M, Rings EH, Verkade HJ, van Dijk TH, Kamps WA, Tissing WJ (2011) Lactose maldigestion during methotrexateinduced gastrointestinal mucositis in a rat model. Am J Physiol Gastrointest Liver Physiol 300:G283-G291

24. El-Ghazaly MA, El-Hazek RM, Khayyal MT (2015) Protective effect of the herbal preparation, STW 5, against intestinal damage induced by gamma radiation in rats. Int J Radiat Biol 91:150-156

25. Lutgens LC, Deutz NE, Gueulette J, Cleutjens JP, Berger MP, Wouters BG, von Meyenfeldt MF, Lambin P (2003) Citrulline: a physiologic marker enabling quantitation and monitoring of epithelial radiation-induced small bowel damage. Int J Radiat Oncol Biol Phys 57:1067-1074

26. Fijlstra M, Tissing WJ, Stellaard F, Verkade HJ, Rings EH (2013) Reduced absorption of long-chain fatty acids during methotrexateinduced gastrointestinal mucositis in the rat. Clin Nutr 32:452-459

27. Blijlevens NM, Lutgens LC, Schattenberg AV, Donnelly JP (2004) Citrulline: a potentially simple quantitative marker of intestinal epithelial damage following myeloablative therapy. Bone Marrow Transplant 34:193-196

28. Derikx JP, Blijlevens NM, Donnelly JP, Fujii H, Kanda T, van Bijnen AA, Heineman E, Buurman WA (2009) Loss of enterocyte mass is accompanied by diminished turnover of enterocytes after myeloablative therapy in haematopoietic stem-cell transplant recipients. Ann Oncol 20:337-342

29. Lutgens LC, Deutz N, Granzier-Peeters M, Beets-Tan R, De Ruysscher D, Gueulette J, Cleutjens J, Berger M, Wouters B, von Meyenfeldt M, Lambin P (2004) Plasma citrulline concentration: a surrogate end point for radiation-induced mucosal atrophy of the small bowel. A feasibility study in 23 patients. Int J Radiat Oncol Biol Phys 60:275-285

30. van Vliet MJ, Tissing WJ, Rings EH, Koetse HA, Stellaard F, Kamps WA, de Bont ES (2009) Citrulline as a marker for chemotherapy induced mucosal barrier injury in pediatric patients. Pediatr Blood Cancer 53:1188-1194

31. Herbers AH, Blijlevens NM, Donnelly JP, de Witte TJ (2008) Bacteraemia coincides with low citrulline concentrations after high-dose melphalan in autologous HSCT recipients. Bone Marrow Transplant 42:345-349

32. Herbers AH, Feuth T, Donnelly JP, Blijlevens NM (2010) Citrulline-based assessment score: first choice for measuring and monitoring intestinal failure after high-dose chemotherapy. Ann Oncol 21:1706-1711

33. van der Velden WJ, Herbers AH, Bruggemann RJ, Feuth T, Peter Donnelly J, Blijlevens NM (2013) Citrulline and albumin as biomarkers for gastrointestinal mucositis in recipients of hematopoietic SCT. Bone Marrow Transplant 48:977-981

34. Vokurka S, Svoboda T, Rajdl D, Sedlackova T, Racek J, Koza V, Trefil L (2013) Serum citrulline levels as a marker of enterocyte function in patients after allogeneic hematopoietic stem cells transplantation - a pilot study. Med Sci Monit 19:81-85

35. Gosselin KB, Feldman HA, Sonis AL, Bechard LJ, Kellogg MD, Gura K, Venick R, Gordon CM, Guinan EC, Duggan C (2014) Serum citrulline as a biomarker of gastrointestinal function during hematopoietic cell transplantation in children. J Pediatr Gastroenterol Nutr 58:709-714

36. Logan RM, Stringer AM, Bowen JM, Yeoh AS, Gibson RJ, Sonis ST, Keefe DM (2007) The role of pro-inflammatory cytokines in cancer treatment-induced alimentary tract mucositis: pathobiology, animal models and cytotoxic drugs. Cancer Treat Rev 33:448-460

37. de Koning BA, van Dieren JM, Lindenbergh-Kortleve DJ, van der Sluis M, Matsumoto T, Yamaguchi K, Einerhand AW, Samsom JN, Pieters R, Nieuwenhuis EE (2006) Contributions of mucosal 
immune cells to methotrexate-induced mucositis. Int Immunol 18: 941-949

38. Logan RM, Stringer AM, Bowen JM, Gibson RJ, Sonis ST, Keefe DM (2008) Serum levels of NFkappaB and pro-inflammatory cytokines following administration of mucotoxic drugs. Cancer Biol Ther 7:1139-1145

39. Bowen JM, White I, Smith L, Tsykin A, Kristaly K, Thompson SK, Karapetis CS, Tan H, Game PA, Irvine T, Hussey DJ, Watson DI, Keefe DM (2015) Pre-therapy mRNA expression of TNF is associated with regimen-related gastrointestinal toxicity in patients with esophageal cancer: a pilot study. Support Care Cancer 23:31653172

40. Miedema KG, de Bont ES, Elferink RF, van Vliet MJ, Nijhuis CS, Kamps WA, Tissing WJ (2011) The diagnostic value of CRP, IL-8, PCT, and sTREM-1 in the detection of bacterial infections in pediatric oncology patients with febrile neutropenia. Support Care Cancer 19:1593-1600

41. Miedema KG, Vermont CL, Ball LM, de Bont ES, Kamps WA, van Tol MJ, Jol-van der Zijde CM, Tissing WJ (2014) The diagnostic value of interleukin- 8 for the detection of bacteremia in pediatric hematopoietic stem cell recipients with febrile neutropenia. Transplantation 98:e80-e81

42. Blijlevens NM, Logan RM, Netea MG (2009) The changing face of febrile neutropenia-from monotherapy to moulds to mucositis. Mucositis: from febrile neutropenia to febrile mucositis J Antimicrob Chemother 63(Suppl 1):i36-i40

43. van der Velden WJ, Herbers AH, Netea MG, Blijlevens NM (2014) Mucosal barrier injury, fever and infection in neutropenic patients with cancer: introducing the paradigm febrile mucositis. Br J Haematol 167:441-452

44. Pelsers MM, Namiot Z, Kisielewski W, Namiot A, Januszkiewicz M, Hermens WT, Glatz JF (2003) Intestinal-type and liver-type fatty acid-binding protein in the intestine. Tissue distribution and clinical utility Clin Biochem 36:529-535

45. Sarikaya M, Ergul B, Dogan Z, Filik L, Can M, Arslan L (2015) Intestinal fatty acid binding protein (I-FABP) as a promising test for Crohn's disease: a preliminary study. Clin Lab 61:87-91

46. Sidler MA, Leach ST, Day AS (2008) Fecal S100A12 and fecal calprotectin as noninvasive markers for inflammatory bowel disease in children. Inflamm Bowel Dis 14:359-366

47. Costa F, Mumolo MG, Bellini M, Romano MR, Ceccarelli L, Arpe P, Sterpi C, Marchi S, Maltinti G (2003) Role of faecal calprotectin as non-invasive marker of intestinal inflammation. Dig Liver Dis 35:642-647

48. Gibson RJ (2009) Gut microbiome and intestinal mucositis: a new challenge for researchers. Cancer Biol Ther 8:512-513

49. Richter KK, Fagerhol MK, Carr JC, Winkler JM, Sung CC, HauerJensen M (1997) Association of granulocyte transmigration with structural and cellular parameters of injury in experimental radiation enteropathy. Radiat Oncol Investig 5:275-282

50. Wedlake L, McGough C, Hackett C, Thomas K, Blake P, Harrington K, Tait D, Khoo V, Dearnaley D, Andreyev HJ (2008) Can biological markers act as non-invasive, sensitive indicators of radiation-induced effects in the gastrointestinal mucosa? Aliment Pharmacol Ther 27:980-987

51. Varela E, Antolin M, Guarner F, Verges R, Giralt J, Malagelada JR (2009) Faecal DNA and calprotectin as biomarkers of acute intestinal toxicity in patients undergoing pelvic radiotherapy. Aliment Pharmacol Ther 30:175-185

52. Menzies IS, Laker MF, Pounder R, Bull J, Heyer S, Wheeler PG, Creamer B (1979) Abnormal intestinal permeability to sugars in villous atrophy. Lancet 2:1107-1109

53. Keefe DM, Cummins AG, Dale BM, Kotasek D, Robb TA, Sage RE (1997) Effect of high-dose chemotherapy on intestinal permeability in humans. Clin Sci (Lond) 92:385-389

54. Gilat T, Ben Hur H, Gelman-Malachi E, Terdiman R, Peled Y (1978) Alterations of the colonic flora and their effect on the hydrogen breath test. Gut 19:602-605

55. Gabrielli M, D'Angelo G, Di Rienzo T, Scarpellini E, Ojetti V (2013) Diagnosis of small intestinal bacterial overgrowth in the clinical practice. Eur Rev Med Pharmacol Sci 17(Suppl 2):30-35

56. Saad RJ, Chey WD (2014) Breath testing for small intestinal bacterial overgrowth: maximizing test accuracy. Clin Gastroenterol Hepatol 12:1964-1972 quiz e119-20

57. van Vliet MJ, Harmsen HJ, de Bont ES, Tissing WJ (2010) The role of intestinal microbiota in the development and severity of chemotherapy-induced mucositis. PLoS Pathog 6:e1000879

58. Koetse HA, Stellaard F, Bijleveld CM, Elzinga H, Boverhof R, van der Meer R, Vonk RJ, Sauer PJ (1999) Non-invasive detection of low-intestinal lactase activity in children by use of a combined $13 \mathrm{CO} 2 / \mathrm{H} 2$ breath test. Scand J Gastroenterol 34:35-40

59. Clarke JM, Pelton NC, Bajka BH, Howarth GS, Read LC, Butler RN (2006) Use of the 13C-sucrose breath test to assess chemotherapy-induced small intestinal mucositis in the rat. Cancer Biol Ther 5:34-38

60. Howarth GS, Tooley KL, Davidson GP, Butler RN (2006) A noninvasive method for detection of intestinal mucositis induced by different classes of chemotherapy drugs in the rat. Cancer Biol Ther 5:1189-1195

61. Tooley KL, Howarth GS, Lymn KA, Butler RN (2010) Optimization of the non-invasive $13 \mathrm{C}$-sucrose breath test in a rat model of methotrexate-induced mucositis. Cancer Chemother Pharmacol 65:913-921

62. Yazbeck R, Howarth GS, Borges L, Geier MS, Smith CL, Davidson GP, Butler RN (2011) Non-invasive detection of a paliferminmediated adaptive response following chemotherapy-induced damage to the distal small intestine of rats. Cancer Biol Ther 12:399-406

63. Tooley KL, Saxon BR, Webster J, Zacharakis B, McNeil Y, Davidson GP, Butler RN (2006) A novel non-invasive biomarker for assessment of small intestinal mucositis in children with cancer undergoing chemotherapy. Cancer Biol Ther 5:1275-1281

64. Keefe DM, Gibson RJ (2006) The combination of oral and small intestinal mucositis, pediatrics and biomarkers: a particularly tricky problem! Cancer Biol Ther 5:1282-1284

65. Ritchie BK, Brewster DR, Davidson GP, Tran CD, McNeil Y, Hawkes JS, Butler RN (2009) 13C-sucrose breath test: novel use of a noninvasive biomarker of environmental gut health. Pediatrics 124:620-626

66. Lutgens LC, Blijlevens NM, Deutz NE, Donnelly JP, Lambin P, de Pauw BE (2005) Monitoring myeloablative therapy-induced small bowel toxicity by serum citrulline concentration: a comparison with sugar permeability tests. Cancer 103:191-199

67. Kissow H (2015) Glucagon-like peptides 1 and 2: intestinal hormones implicated in the pathophysiology of mucositis. Curr Opin Support Palliat Care 9:196-202 